\title{
Por que regular os serviços públicos? ${ }^{\mathrm{I}}$ *
}

\author{
Harold Demsetz ${ }^{+}$
}

University of Chicago, Illinois, United States

University of California, Los Angeles, California, United States

Resumo: A teoria econômica moderna define a regulação dos mercados de serviços públicos como necessária em razão de uma suposta baixa competitividade nesses mercados. E embora os métodos regulatórios utilizados nesses setores venham sendo constantemente criticados por sua ineficiência, a crença de que as regulamentações são necessárias se manteve inalterada. Neste artigo, procura-se analisar e comprovar que os argumentos econômicos convencionais que justificam as regulações governamentais nos serviços públicos se baseiam em premissas equivocadas sobre o funcionamento desses mercados.

Palavras-chave: Regulação, Serviços públicos, Concorrência, Monopólio.

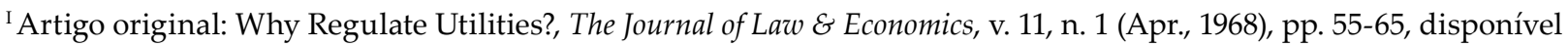
em: https://www.jstor.org/stable/724970. Tradução de Joao Felipe Rodrigues Lanza, (100000-0001-5048-0979, estudante de Administração de Empresas da Fundação Getúlio Vargas, e pesquisador acadêmico com ênfase na área de transporte ferroviário. E-mail: joaorod95@gmail.com

${ }^{*}$ Nota original: $\mathrm{O}$ autor se encontra em débito com R.H. Coase, que já desconfiava da teoria do monopólio natural, muito antes deste artigo ter sido escrito, e a George J. Stigler e Joel Segall, pelos comentários e críticas construtivas. 


\title{
Why regulate utilities?
}

\begin{abstract}
The modern economic theory defines regulation as a necessary measure in utilities' markets due to a supposed low compettitivity in those industries. Altough the regulatory methods which ar used in those industries have been consantly criticised for their inefficiency, th belief that the regulations are necessary has been kept unchanged. Therefore, the obective of this article is to prove that the convencional economic arguments that justify regulation in utilities are based on misled premises about these industries' dynamics.
\end{abstract}

Keywords: Regulation, Utilities, Competition, Monopoly.

\section{¿Por qué regular los servicios públicos?}

Resúmen: La teoría económica moderna define la regulación de los mercados de servicios públicos como necesaria debido a su supuesta baja competitividad en estos mercados. Y aunque los métodos regulatorios utilizados en estos sectores han sido constantemente criticados por su ineficiencia, la creencia de que las regulaciones son necesarias no ha cambiado. Este documento busca analizar y probar que los argumentos económicos convencionales que justifican la regulación gubernamental en los servicios públicos se basan en suposiciones erróneas sobre el funcionamiento de estos mercados.

Palavras clave: Reglamento, Servicios Públicos, Competencia, Monopolios. 
A doutrina econômica atual fornece, aos estudantes, uma relação básica entre o número de firmas, produzido em um dado mercado, e o grau de resultados competitivos que prevalecerão. Declarado explicitamente ou sugerido implicitamente, é a doutrina de que o preço e a produção podem divergir em maior medida, a partir de seus níveis competitivos quanto menor for o número de empresas produzindo nesse mercado. Essa relação tem fornecido a lógica que motiva grande parte da pesquisa dedicada ao estudo de concentrações industriais, e fornecido suporte considerável para a regulação ${ }^{1}$ dos setores de serviços públicos.

Nesse artigo, eu argumentarei que a concentração e a competição não são derivadas das relações teóricas existentes, e que isso é amplamente baseado em um entendimento incorreto das concepções de competição e rivalidade. A aplicação mais forte da relação em questão se dá na área de serviços públicos, uma vez que se assumirmos economias de escala na produção, apenas uma firma irá produzir os bens ou serviços naquele mercado. A validade lógica ou a falsidade da relação afirmada deve se revelar mais claramente nesse caso.

Embora a regulamentação de serviços públicos venha sendo criticada recentemente por sua ineficácia ou pelos efeitos indesejados (STIGLER; FRIEDMAN, 1962), os argumentos intelectuais básicos para acreditar que a regulação é verdadeiramente eficaz não foram contestados. Mesmo aqueles que estão inclinados a rejeitar a regulamentação governamental ou a propriedade estatal de serviços públicos, porque acreditam que essas alternativas são mais indesejáveis que os monopólios privados, implicitamente aceitam os argumentos intelectuais subjacentes à regulamentação².

A teoria econômica do monopólio natural é incrivelmente curta, e como veremos, incrivelmente obscura. A doutrina atual é refletida em duas afirmações teóricas. Samuelson (1964, s/p) escreve:

Sob constantes custos decrescentes para as firmas, uma ou algumas empresas expandirão suas produções de forma que tomarão uma parcela significativa do total do mercado. Nós então terminaríamos com (1) uma única firma monopolista dominando toda a indústria; (2) um pequeno grupo de grandes firmas dominando o mercado... ou (3) alguma forma de competição imperfeita que, ou é estável ou se encontra em uma intermitente guerra de preços, em uma notória ruptura do modelo econômico de competição "perfeita" no qual nenhuma firma tem controle sobre os preços ou o mercado.

Alchian e Allen (1964, s/p) veem o problema da seguinte forma:

Se um produto é produzido em condições de custos nas quais uma maior produção signifique menor custo médio por unidade... Apenas uma firma poderá sobreviver; se houver duas empresas, uma poderia expandir sua produção visando reduzir os custos e assim eliminar a concorrente.

\footnotetext{
${ }^{1}$ A legislação antitruste, na medida que foi motivada por uma preocupação com concentrações industriais, também se beneficiou da relação descrita sobre poder de monopólio e estruturas de mercado.

${ }^{2}$ Milton Friedman, enquanto descreve sua preferência por monopólios privados sobre monopólios públicos, escreve: "Entretanto, monopólios também podem surgir por ser tecnicamente mais eficiente possuir um único produtor ou empresa... Quando as condições técnicas tornarem um monopólio o resultado natural das forças competitivas de mercado, há apenas três alternativas aparentemente disponíveis: monopólio privado, monopólio público ou regulação pública" (FRIEDMAN, 1962, p. 28).
} 
Em razão da impossibilidade de mais de uma firma ser lucrativa, duas (firmas no mercado) é muito. Mas se houver apenas um produtor, este poderá elevar os preços acima dos custos de livre entrada por um longo tempo. Qualquer um dos recursos é desperdiçado ou porque há muitas empresas no mercado, ou se houver apenas uma, esta poderá cobrar preços de monopólio.

Neste ponto, será útil explicar explicitamente a interpretação do monopólio natural, utilizada neste artigo. Se por causa de produções de escala, for menos custoso, para apenas uma empresa, produzir o bem ou serviço do que duas ou mais empresas, apenas uma irá sobreviver; e se não houver regulações, a firma em questão cobrará preços de monopólio, visto que a decisão de preço e produção será tomada visando maximizar o lucro, com a única restrição da demanda do mercado, pelo produto em questão.

A teoria do monopólio natural é deficiente porque não revela a lógica que leva economias de escala a preços de monopólio no mercado. Para ver isso de forma mais clara, vamos considerar o processo desde o início.

Por que rivais devem compartilhar o mercado? Produtores concorrentes podem oferecer contratos com compradores. Nessa competição de licitações, o participante, que oferecer os termos mais favoráveis, conseguirá mais sucesso; não há razão clara ou necessária para licitar empresas concorrentes para compartilhar a produção, e não há nenhuma razão clara para a competição em licitações resultar em um aumento nos custos unitários.

Por que o resultado do mercado não regulado deve ser o preço de monopólio? A competitividade do processo de licitação depende muito de variáveis como o número de licitantes, mas não há razão clara para que economias de escala reduzam o número de participantes. Deixemos que os compradores solicitem licitações para atender as suas demandas. Economias de escala não implicam, de modo algum, que haverá apenas um participante na licitação. Podem haver muitos licitantes e o vencedor ser o menor. A existência de economias de escala é irrelevante, para a determinação de participantes em uma licitação. Se o número de licitantes for grande ou se, por outras razões, o conluio entre eles for impraticável, o custo deverá ser bem próximo do custo unitário de produção ${ }^{3}$.

Os determinantes da concorrência, nas negociações de mercado, divergem e não devem ser confundidos com o número de empresas responsáveis pela produção, após as negociações contratuais serem concluídas. A teoria do monopólio natural é claramente obscura. Economias de escala na produção implicam que as propostas, apresentadas no mercado, ofereçam quantidades crescentes a custos unitários mais baixos, mas não implicam, de nenhuma forma óbvia, no quão competitivos serão os preços. Se um produtor puder fazer o trabalho a um custo menor que dois ou mais, porque cada um teria uma menor produção, então, o produtor com o menor preço de licitação para todo o contrato, será premiado com a tarefa, seja o bem produzido cimento, eletricidade, máquinas de venda automáticas ou o que quer que seja, mas o menor preço da oferta não precisa ser um preço de monopólio ${ }^{4}$.

\footnotetext{
${ }^{3}$ Eu não considerarei, neste artigo, o problema da precificação do custo marginal e diversos dispositivos, como tarifas múltiplas, que podem ser usadas para a precificação do custo marginal.

${ }^{4} \mathrm{O}$ conceito de competição, empregado aqui não é novo na Economia, apesar de ser negligenciado há tempos. Uma definição primitiva do conceito, conhecida como "competição no campo", em contraste com a "competição dentro do campo", é feita por Edwin Chadwick (1859).
} 
A crítica, feita aqui da teoria do monopólio natural, pode ser melhor entendida, construindose um exemplo livre de complicações irrelevantes, como a durabilidade dos sistemas de distribuição, incerteza e comportamento irracional, o que pode, ou não, justificar o uso de comissões regulatórias, mas nenhuma delas é relevante para a teoria do monopólio natural; visto que esta teoria depende de uma única crença: os preços e a produção serão de monopólio se, devido à economias de escala, apenas uma empresa conseguir obter êxito na produção.

Assumamos que os proprietários de automóveis são obrigados a possuir e dispor de uma licença anual. A produção de licenças é sujeita às economias de escala.

A teoria do monopólio natural afirma que, sob essas condições, os proprietários de automóveis irão comprar licenças de apenas um produtor, e que esta empresa, na ausência de regulação, cobrará preços de monopólio restritos unicamente pela demanda e pelo custo de produção das licenças. A lógica desse exemplo dita que as licenças serão compradas de uma única firma, baseado no custo unitário mais baixo possível. Mas por que esse preço seria um preço de monopólio?

Podem haver muitos licitantes no contrato anual. Cada um irá submeter uma oferta, baseada na premissa de que, se a oferta for a mais baixa, venderá para todos os clientes, e que se não for, não venderá para nenhum. Nessas condições, existiram licitantes suficientes, agindo de forma independente, visando garantir que o preço vencedor divergirá de forma insignificante do custo unitário de produção das licenças. Se apenas uma empresa oferecer o preço mais baixo, o processo termina, mas se duas ou mais firmas oferecerem o preço mais baixo, uma delas é selecionada, de acordo com alguma seleção aleatória ou pela venda de contrato de uma empresa para outra. Não há preços de monopólio, apesar de talvez haver aumento de renda para alguns produtores, se o aumento da oferta for positivo. O preço é determinado pelo mercado. O único papel do governo ou de uma cooperativa de consumidores é a seleção do vencedor do contrato, se houver mais de um licitante oferecendo o preço mais baixo.

Há apenas duas premissas importantes: (1) o input necessário para a entrada no mercado deve estar disponível para muitos potenciais licitantes a preços determinados, em livre mercado. Isso confere credibilidade à diversas ofertas rivais. (2) $\mathrm{O}$ custo do conluio entre rivais deve ser proibitivamente alto. O leitor irá reconhecer que esses requerimentos não são diferentes daqueles exigidos para evitar monopólios em qualquer mercado, esteja a produção sujeita, ou não, à economias de escala.

Além disso, se estamos dispostos a considerar a possibilidade de conluio ou fusão entre todos os potenciais rivais em uma perspectiva razoável, então devemos examinar o outro lado da moeda. Por que o custo do conluio entre ofertantes rivais deve ser proibitivamente alto, se um infinito número de rivais pode se unir com sucesso? Se conferirmos, aos consumidores, o acesso às mesmas ferramentas, o mercado será caracterizado por negociações bilaterais entre produtores organizados e consumidores organizados. Enquanto o resultado dessa organização é incerto quanto à distribuição de renda, não há razão para se esperar ineficiência.

Apenas a elasticidade da oferta dos licitantes e os custos do conluio são questões a serem respondidas empiricamente, visto que elas não podem ser deduzidas de economias de escala. Existe mais de uma firma em todo setor de serviços públicos e diversas firmas em algumas indústrias de utilidade pública. E isso é verdade, mesmo quando as restrições à entrada são 
severas; essa afirmação, de que a oferta de potenciais participantes em qualquer mercado seria muito inelástica se as restrições de licenciamento pudessem ser abolidas, pareceria difícil de defender, se produzisse concorrentes em mercados próximos.

A presença de rivalidade ativa é claramente indicada na história dos serviços públicos. De fato, a produção de concorrentes, para não falar licitantes sem sucesso, era tão abundante, que se começa a duvidar que as economias de escala caracterizavam as indústrias de serviço público, no momento em que a regulamentação substituiu a concorrência no mercado. Eram comuns reclamações de que as ruas se encontravam frequentemente em obras, com a finalidade de acomodar empresas concorrentes. Behling escreve (1938, p. 19-20):

Dificilmente há cidades no país que não tenham presenciado a competição em uma ou mais indústrias de serviços públicos. Seis companhias elétricas estavam organizadas no ano de 1887 em New York. Quarenta e cinco empresas de luz possuíam licença para atuar em Chicago em 1907. Antes de 1895, Duluth, Minnesota, era servida por cinco empresas de iluminação, e Scranton, Pennsylvania, tinha quatro em 1906... No final do Século XIX a competição era comum na indústria de gás em todo o país. Antes de 1884, seis companhias concorrentes operavam em New York... A competição era comum e persistente na indústria de telefonia. De acordo com um relatório especial de 1902, de 1051 cidades nos Estados Unidos com uma população superior a 4.000 habitantes, 1002 contavam com instalações telefônicas. As companhias independentes tinham monopólio em 137 cidades, o grupo Bell tinha controle exclusivo na comunicação telefônica em 414 cidades, enquanto as 451 restantes tinham serviços duplicados. Baltimore, Chicago, Cleveland, Columbus, Detroit, Kansas City, Minneapolis, Philadelphia, Pittsburgh, e St. Louis, dentre as maiores cidades, tinham ao menos duas companhias telefônicas em 1905.

Parece que o número de possíveis rivais em licitações e o custo do conluio, nas diversas indústrias de serviços públicos, provavelmente, será pelo menos grande, como em vários outros setores nos quais os mercados não regulamentados funcionam, de forma razoavelmente boa.

A teoria do monopólio natural não fornece base para preços de monopólio. A teoria é ilógica. Além disso, para o caso geral das indústrias de serviços públicos, parece não haver evidências claras de que o custo do conluio é significativamente mais baixo do que os mercados nos quais a competição desregulada parece funcionar. Na medida em que a regulação dos serviços públicos é baseada no medo de preços de monopólio, simplesmente porque uma única empresa atenderá todo o mercado, não sendo, assim, baseado em nenhum teorema econômico logicamente dedutível.

O ponto importante que precisa de destaque é que não possuímos nenhuma teoria que nos permita deduzi a partir do grau de concentração em um mercado específico quando os preços e produção são competitivos. Ainda, não temos nenhuma teoria geral de conluio e certamente nenhuma que nos permita associar a concentração observada em um mercado com práticas de conluio bem sucedidas. (STIGLER, 1984, s/p)

É possível fazer algumas afirmações sobre o conluio, que revelam a natureza das forças no mercado. Essas afirmações são amplamente intuitivas e não podem ser perseguidas em detalhes aqui. Mas elas podem ser úteis para transmitir ao leitor uma noção do que se entende por uma teoria de conluio. 
Vamos supor que não há custos especiais para competir. Isto é, nós assumimos que os vendedores não precisam acompanhar os preços de outras atividades de seus concorrentes. Segundo, suponhamos que há alguns custos de conluio que devem ser suportados por membros de um cartel de licitantes. Esta condição é menos aproximada, onde o governo subsidia o custo de conluio - por exemplo, o Departamento de Agricultura dos Estados Unidos. Finalmente, suponhamos que não haja barreiras à entrada.

Sob essas condições, novos rivais serão pagos para participar do conluio. Em troca da adesão, eles receberão uma parcela proporcional do lucro do monopólio. À medida que mais concorrentes aparecem, a participação proporcional deve cair. $\mathrm{O}$ cartel vai continuar pagando, para que novos competidores entrem, até que a proporção caia ao custo do conluio. Isto é, até que os membros do cartel recebam uma taxa competitiva de retorno para permanecer no cartel. O próximo concorrente pode se recusar a participar no cartel; em vez disso, ele pode entrar no mercado a um preço inferior ao preço do cartel (como qualquer membro do cartel, que escolhe romper o acordo). E se existe algum atrito no sistema, esse concorrente vai escolher esse curso de ação, em vez de se juntar ao cartel, pois, se ele se junta ao cartel, ele recebe uma taxa de retorno competitiva; enquanto que, se competir fora do cartel, vendendo a um preço abaixo (do cartel), ele recebe uma taxa acima da competitiva de retorno para algum período de curto prazo. Sob as condições assumidas, o cartel deve eventualmente falhar e o preço de saída pode ser competitivo, embora apenas algumas empresas realmente produzam o produto. Além disso, o essencial ingrediente, para a sua eventual falha, é apenas que o custo da empresa do conluio exceda o custo da competição.

Em que condições, o custo de conluio excederá o custo da competição? Como esses custos serão afetados pela permissão de táticas coercitivas? E quanto aos carteis de compradores? Quais fatores afetam quanto tempo é "eventualmente"? Tais questões continuam a ser respondidas por uma teoria do conluio. Até essas questões serem respondidas, as prescrições de políticas públicas devem ser suspeitas. Um mercado, em que muitas empresas produzem o que pode ser competitivo ou pode ser colusivo; o grande número de empresas apenas reflete deseconomias de escala na produção; amplos números não refletem necessariamente altos ou baixos custos de conluio. Um mercado, em que poucas firmas produzem, pode ser competitivo ou ser conclusivo; o pequeno número de produtores apenas reflete economias de escala na produção; poucos produtores não necessariamente refletem altos ou baixos custos de conluio. Então, um economista pode ver muitos varejistas que vendem, em termos de "comércio justo", com suspeita e se maravilhar com a capacidade de um grande número de trabalhadores e de sindicatos eficazes e, no entanto, olhar com pouca admiração para o desempenho das poucas empresas, que vendem aviões, câmeras ou automóveis.

O tema dos preços de monopólio é necessariamente permeado pelo assunto de negociar ou contratar custos. Um mundo em que os custos de negociação são iguais a zero, é um mundo no qual nenhuma ineficiência monopolista estará presente, simplesmente porque compradores e vendedores podem lucrar com negociações, que resultam em uma redução e eliminação de ineficiências.

Em tal mundo, serão as habilidades de barganha e não as estruturas de mercado que determinarão a distribuição de riqueza. Se existe uma estrutura monopolista em um lado do mercado, o outro lado será organizado para compensar qualquer poder implícito pela 
estrutura monopolista. A organização do outro lado do mercado pode ser realizada por membros desse lado ou por rivais da estrutura monopolista, que permanecem no primeiro lado. A coexistência de poder de monopólio e estruturas de monopólio é possível somente se os custos de negociação forem diferencialmente positivos, sendo menores para um conjunto de vendedores ou compradores, do que para vendedores ou compradores rivais. Se um conjunto de vendedores ou compradores consegue organizar aqueles do outro lado do mercado, de forma mais barata que os rivais conseguem, o preço pode ser aumentado ou diminuído até que a extensão do diferencial existente supere os custos de negociação; essa extensão será menor que o preço de monopólio simples. Em alguns casos, a vantagem diferencial na negociação dos custos pode ser tão grande, que o preço se instalará no nível de monopólio (monopsônio). Esse certamente não pode ser o caso geral, mas a probabilidade disso, certamente, aumenta os custos impostos aos potenciais rivais; a restrição legal da entrada é uma maneira de aumentar as desvantagens diferenciais para os rivais; o significado econômico de restringir a entrada é aumentar o custo dos potenciais rivais de negociar e organizar compradores ou vendedores.

A questão da política pública é quais grupos de participantes do mercado, se houver, devem receber vantagens e desvantagens do governo, não apenas na subvenção ou tributação da produção, mas também na criação de vantagens ou desvantagens, na condução das negociações.

Nessa conjuntura, deve ser enfatizado que eu argumentei, não que comissões regulatórias são indesejáveis, mas que a teoria econômica atualmente não fornece uma justificativa para as comissões, na medida em que a crença de que a concentração e os preços de monopólio possuem alguma relação entre si.

De fato, a regulação nos serviços públicos tem sido frequentemente procurada por causa dos inconvenientes da competição. A história da regulação é comumente escrita, em função do desejo de proibir duplicações "excessivas" dos sistemas de distribuição e capturas de ganhos inesperados pelas empresas. Nenhum desses aspectos dos negócios de serviços públicos está relacionado às economias de escala. Vamos primeiro considerar o problema da duplicação excessiva das instalações.

Duplicação de instalações. As comunidades, e não os indivíduos, detêm ou controlam a maioria dos direitos de uso do solo e espaço utilizado pelas empresas de serviços públicos. $\mathrm{O}$ problema da duplicação excessiva de sistemas é atribuível à incapacidade das comunidades, em precificar esses recursos escassos. O direito de usar as vias públicas é um recurso escasso. A ausência de um preço para o uso desses recursos, é um preço alto o suficiente para refletir os custos de oportunidade de tais alternativas como serviço de tráfego ininterrupto e visualizações não marcadas, para a sua duplicação excessiva. A fixação de uma taxa apropriada, para o uso desses recursos, reduziria o grau de duplicação para níveis ótimos.

Considere que a porção do solo, controlada por um indivíduo e sob a qual o sistema de distribuição de serviços públicos é utilizado. Confronte esse indivíduo, com a opção de um serviço a um preço mais baixo de uma empresa que é rival do presente vendedor. O indivíduo levará em consideração o custo de correr uma trincheira através de seu jardim e o benefício de receber o serviço a um custo mais baixo. Não há necessidade de duplicação excessiva. De fato, não há necessidade de qualquer duplicação de instalações, se ele selecionar o novo serviço, 
dado que uma das duas condições é válida. Se o indivíduo possui uma parte do sistema de distribuição sob seu solo, ele poderia ligá-la a qualquer linha tronco que lhe sirva melhor; alternativamente, uma vez que a nova empresa ganhe o seu apoio, uma solução racional do uso dessa parte do sistema de distribuição seria a companhia proprietária vendê-la, para a empresa que agora serve esse comprador.

Podem haver boas razões para o uso de terrenos públicos, em vez de privados para abrigar as linhas tronco de alguns sistemas de distribuição. A instalação de tais sistemas sob ou sobre ruas, becos, e calçadas, recursos já públicos (um fato tomado como dado aqui) pode ser menos custoso, que passando-os por propriedades privadas. $\mathrm{O}$ fracasso das comunidades em precificar, de forma adequada, a propriedade pública pode ser explicada de três formas:

1. Houve uma falha em entender as pré-condições para o uso eficiente dos recursos. Alguns funcionários devem receber incentivos para atuar como conservadores racionais desses recursos, quando eles são escassos.

2. A interrupção das vias não era, de fato, cara o suficiente para incomodar.

3. A fixação de taxas, para reduzir o uso excessivo de passagem pelas empresas, era muito cara para ser prática.

As duas primeiras explicações, se verdadeiras, não dão suporte para o argumento da regulação das empresas de serviços públicos. A terceira explicação pode dar suporte a alguns tipos de regulação, pois afirma que os efeitos econômicos, produzidos pela colocação de sistemas de distribuição, são tais que é muito caro economizar, através do uso de um sistema de preços. $\mathrm{O}$ custo de se considerar esses efeitos, através de um processo regulatório, deve ser comparado com os benefícios de realinhar o uso de recursos, e se os benefícios compensam os custos, algumas regulamentações podem ser desejáveis. Note claramente: Economias de escala para servir a um mercado não estão em questão. Para ver isso, imagine que os sistemas de distribuição elétrica são linhas finas de uma tinta condutora especial. A colocação de tais sistemas não causa dificuldades. Eles são pulverizados sobre propriedade pública ou privada. No entanto, suponha que o uso de cada sistema esteja sujeito às economias de escala. Claramente, o desejo de regulamentações não pode agora ser justificado por tais problemas como a interrupção do tráfego, embora as economias de escala estejam presentes. O "excesso" de duplicações é um problema de externalidades e não de economias de escala.

Vamos supor que seja desejável empregar algum tipo de regulação, porque é muito dispendioso utilizar o sistema de preços para se considerar as perturbações, decorrentes da colocação dos sistemas de distribuição. A regulação vem em todos os tamanhos e formas, e não há forma clara de que tipo de regulação seria mais desejável.

Um sistema de franquias que permite que apenas um número limitado de empresas de serviços públicos sirva uma área de mercado, tem sido empregado com frequência. Um sistema de franquias, que concedesse a franquia à companhia que oferecer o melhor preço, seria aquele 
que permitisse a concorrência no mercado, entre os licitantes rivais para a determinação do preço. A restrição do mercado seria substituída pela da comissão regulatória.

Um arranjo alternativo seria a propriedade pública dos sistemas de distribuição. Isso envolveria a coleta de licitações concorrentes, para a instalação dos sistemas. Os sistemas podem então ser instalados pelo licitante que se oferecer a fazer o trabalho pelo menor preço. Esse é o mesmo processo usado pelas comunidades, para construir estradas e emprega licitação rival e não comissões para determinar o preço. A comunidade poderia então permitir que o sistema de distribuição a ser utilizado por essa empresa de serviços públicos ao menor custo para os residentes. Mais uma vez, o mercado é substituído pela comissão de regulação. A propriedade pública das ruas pode fazer com que a propriedade pública dos sistemas de distribuição pareça desejável, mas isso não significa que o uso de comissões regulatórias seja desejável.

O problema dos ganhos inesperados: devemos agora considerar uma última dificuldade que tem, por vezes, sido organizada para apoiar a regulamentação dos serviços públicos. Esse argumento se baseia no fato de que os eventos na vida são incertos. A aplicação dessa observação, para o negócio de serviços públicos, é assim. Depois que um comprador entra em um acordo com uma empresa de serviços públicos para o fornecimento de serviços, pode haver mudanças na tecnologia e preços, que tornem o preço acordado obsoleto.

Nesses casos, se afirma que o preço deve ser alterado para refletir o custo atual do fornecimento dos serviços públicos. A regulação por comissão de preços, com base nos custos atuais, é necessária na indústria de serviços públicos, devido à durabilidade dos investimentos originais nas instalações e distribuição. Essa durabilidade proíbe o uso de recontratações no mercado, como um método para provocar mudanças apropriadas no preço.

Problemas de incerteza criam um potencial para ganhos inesperados ou negativos. Se as negociações de mercado desconsideram o desenvolvimento de uma tecnologia melhor e se há algum custo para a reaquisição de contratos, para outros produtores, uma vez que eles são acordados, então, uma melhoria inesperada na tecnologia utilizada por aqueles que recebem os contratos, pode gerar um preço maior do que o custo unitário, mas maior por um valor menor que o custo de reaquisição dos contratos. Nesses casos, as empresas, que agora detêm os contratos, podem coletar um ganho inesperado positivo por um período de curto prazo. Ou se os preços dos insumos aumentam mais que o esperado, essas mesmas empresas podem sofrer uma perda inesperada. Mas a mesma coisa é verdadeira em todos os mercados. Se um cliente compra ovos hoje, para o consumo amanhã, ele vai desfrutar de um ganho positivo inesperado se o preço dos ovos for maior amanhã, e uma perda inesperada, se o preço for menor.

A diferença nos dois casos é que, quando a longo prazo, os contratos são desejáveis, os lucros podem continuar por períodos mais longos. Nesses casos, pode ser desejável empregar um esquema regulatório de custos, que insira uma cláusula que reserve o direito, por alguma taxa, de renegociação dos contratos.

O problema, enfrentado aqui, é qual a melhor maneira de lidar com a incerteza. Contratos de longo prazo para o fornecimento de commodities, são concluídos satisfatoriamente no mercado, sem o auxílio de regulamentações. Esses contratos podem ser entre os varejistas e 
os produtores de equipamentos, ou entre as companhias aéreas e fabricantes de aeronaves, que podem usar instalações produtivas duráveis. $\mathrm{O}$ aluguel de escritórios por noventa e nove anos é repleto de incertezas. Eu presumo que as partes de um contrato consultem especialistas, para fornecer opiniões relevantes sobre essas questões e que o contrato celebrado resolva (essas questões) de uma forma satisfatória para ambas as partes. As sanções, pela reabertura das negociações em uma data posterior, podem ser incluídas no contrato. Eu presumo que compradores e vendedores, que concordem em contratar um ao outro, já tenham lidado com o problema da incerteza de maneira mutuamente satisfatória. A maneira correta de ver o problema é escolher o melhor tipo de contrato. Um produtor pode dizer: "Se você concordar em comprar de mim, por vinte e cinco anos, eu posso usar instalações que, espera-se, produzam a mercadoria a custos mais baixos; se você contratar por cinco anos, eu não vou investir muito em equipamentos, e vou incorrer em preços mais altos, para cobrir os maiores custos unitários - claro, o contrato de longo prazo permite mais tempo para o inesperado, então, vamos incluir uma cláusula de escape de algum tipo". O comprador e vendedor devem então concordar com um contrato adequado; durabilidade do equipamento e comprometimento de longo prazo podem ser sacrificados a maiores custos unitários, mas não há razão para esperar que o contrato concluído seja tendencioso, quanto ao resultado, ou não ser ótimo em alguns aspectos.

A regulação da taxa de custo adicional é a melhor forma de lidar com esses problemas, mas tem grandes incertezas próprias. A comissão será eficaz? Um arranjo de custo benefício bem definido criará um sistema inadequado de incentivos que oriente a empresa em suas políticas de investimento e operacionais? As incertezas contínuas associadas aos custos adicionais levam a outras dificuldades evitáveis na formulação de planos de investimento? A regulação de taxas por comissões, ao invés da rivalidade de mercado pode ser mais apropriada para as indústrias de serviços públicos do que para outras (indústrias), mas a verdade dessa afirmação não pode ser estabelecida de forma dedutiva, a partir da teoria econômica existente. Nós não sabemos se a regulação lida com o problema da incerteza de forma melhor ou pior que o mercado.

O problema de lidar com os ganhos inesperados deve ser distinguido do problema dos aluguéis previsíveis. Suponha que se saiba que os compradores incorrerão em custos de recontratação consideráveis, se decidirem alterar os vendedores depois de um contrato celebrado já ter sido parcialmente cumprido.

Parece que o vendedor, que vencer o contrato inicial, será capaz de recolher uma renda tão grande quanto esse custo de recontratação. Mas isso não é verdade se o custo de recontratação for previsível, isto é, se não é um golpe de sorte. A licitação para o contrato inicial levará em conta a renda previsível, de modo que, se a licitação for competitiva, a renda será perdida pelos preços de oferta mais baixos, aos quais ela dá origem.

Em que medida a legislação e a regulamentação devem substituir o mercado de serviços públicos ou em outras indústrias, e quais as formas que tal legislação deveria ter? Não é o objetivo deste artigo fornecer respostas a tais questões. Meu propósito tem sido questionar os argumentos econômicos convencionais, para a legislação e regulamentação existentes. Uma participação expandida do governo pode ser defendida, com base empírica de uma superioridade geral, documentada da administração pública dessas indústrias ou por uma 
preferência filosófica para o socialismo moderado. Mas eu não vejo como uma defesa pode ser baseada nos argumentos formais considerados aqui; esses argumentos não nos permitem deduzir a partir de suas suposições, quer o problema do monopólio ou a superioridade administrativa da regulação.

No caso dos serviços públicos, recorrer à competição do mercado aliviaria as comissões dos desconfortos da regulamentação. Mas isso também os aliviaria do conforto de mercados legalmente protegidos. Minha crença é de que a rivalidade do livre mercado disciplina (o mercado), de forma mais eficaz que os processos regulatórios de comissões. Se os administradores das empresas de serviços públicos duvidam dessa crença, sugiro que reexaminem a história de sua indústria, para descobrir quem foi que forneceu mais força, por trás do movimento regulatório.

\section{Referências}

ALCHIAN, Armen; ALLEN, William R. University Economics. University Economics, v. $412,1^{\text {st }}$ ed, 1964.

ALCHIAN, Armen; KESSEL, Reuben Kessel. Competition, Monopoly, and the pursuit of pecuniary gain. Aspects of labor economics, v. 157, 1962.

AVERCH, H; JOHNSON, L. The firm under regulatory constraint. Am. Econ. Rev., v. 55, n. 1052, 1962.

BEHLING, Burton N. Competition and monopoly. Public utility industries, p. 19-20, 1938.

CHADWICK, Edwin. Results of different principles of legislation and administration in Europe: Service 22. J. Royal Society, v. 22, n. 381, 1859.

STIGLER, George J. A theory of oligopoly. J. Pol. Econ., v. 44, 1984.

STIGLER, George; FRIEDMAN, Claire. What can regulators regulate? The case of electricity. J. Law \& Econ., v. 1., n. 5, 1962.

FRIEDMAN, Milton. Capitalism and Freedom. Chicago: Chicago Press, 1962.

SAMUELSON, Paul A. Economics, v. 461, $6^{\text {th }}$ rev, 1964.

RECEBIDO EM: 28/06/2019

APROVADO EM: 31/10/2019 